\title{
Subjective Posture and Subjective Affluence: Chicago Field Theories in the U.S. Media and Political Systems
}

Kevin G. Barnhurst ${ }^{1}$, Richard Besel ${ }^{2}, \&$ Christopher Bodmann $^{1}$

1 Department of Communication, University of Illinois at Chicago, Chicago, IL 60607, USA

2 Department of Communication Studies, California Polytechnic State University, San Luis Obispo, CA 93407, USA

To further understanding of how individuals experience media and political systems, this article compares a project in the Chicago sociology tradition to concepts from Bourdieu's field theory and practical reason. Limited life history documents from Chicago working-class and moreadvantaged young adults illustrate two interactionist concepts, subjective posture, one's stance toward media and politics, and subjective affluence, the range of empowerment the postures reveal. A stance as individual consumer, primarily in pursuit of entertainment, crossed over class lines, but elite participants had higher subjective affluence, with agency as political actors influencing others. The similarities illustrate an aspect of Bourdieu's habitus, and their class differences illustrate distinctions in symbolic power. The results advance theory in the midrange between macrolevel structures and microlevel subjectivity.

In 1956, Four Theories of the Press argued that a media system, especially the press, "takes on the form and coloration of the social and political structures" where it operates (Siebert, Peterson, \& Schramm, 1956, pp. 1-2). Despite its influence on comparative analyses of media systems, the book takes an overly simplified view of mediated and political communication, built on mid-20th-century assumptions about human nature, government, and truth (Altschull, 1984; Nerone, 1995).

Recent work sees the media and political systems as mutually influential and historically situated — sometimes politics influences media and sometimes media influence politics (Hallin \& Mancini, 2004). Instead of a narrative of inevitable progress toward a single liberal Western 
ideal, the more recent Comparing Media Systems proposed liberal, democratic corporatist, and polarized pluralist models based on circulation, parallelism, professionalism, and regulation of media (Hallin \& Mancini, 2004). Besides needing to engage nations outside of Europe and North America (e.g., Graber, 2006; Jones, 2008; McQuail, 2005), the models could expand in other ways.

Like other systems analyses of relationships between media and politics, Comparing Media Systems does not investigate how the macrolevel of media and political systems also interacts with the microlevel of subjective, individual experience. The book does cite Pierre Bourdieu to argue, for example, that journalism standards look similar to what Bourdieu calls a cultural field, a "sphere of social action with its own 'rules of the game,' standards of practice, and criteria of evaluation"(Hallin \& Mancini, 2004, p. 81). But Bourdieu also proposes microlevel ideas.

To engage with and expand understanding of the relationships between macrolevel structures and microlevel experiences of individuals with media and political systems, we review Bourdieu's field theory and the notions of habitus, social space, and symbolic capital from his theory of practical reason. On that background, we situate works following the tradition of the Chicago School of sociology, which use comparative methods to study individual, subjective experience within media and political systems. The research, using life history techniques to bridge the divide between macrosystems and microindividual experience, has for the American case so far included only collegiate participants, and to fill the gap we present an analysis that includes U.S. life histories from less-educated participants. We then discuss the relationship between field theory and the concepts growing out of research based on the older Chicago tradition. Our aim is to discover whether Bourdieu and Chicago theory together would take better account of individual political agency within comparative analyses of media systems. 


\section{Literature I: Bourdieu and comparative analyses of objective systems}

A "most often quoted sociologist" and "symbol of theoretical distinction" (Neveu, 2007, p. 335), Bourdieu has only recently become accepted among scholars of political communication and media studies, reversing an earlier refusal of his sociology (Guillory, 2000). Perhaps because his work mentions journalism and media only in passing, communication scholars were slow to accept his ideas. Even when he turned to topics media scholars care about, as in On Television (his video lecture; Bourdieu, 1996), “many Anglo - American media researchers” greeted him “with profound disappointment" ( Hesmondhalgh, 2006, p. 211). One reason communication researchers have now turned to his work is that Bourdieu's theoretical framework allows them "to think relationally, to move from macro to micro, to go beyond binary choices such as structure versus agency" (Neveu, 2007, p. 336). Following his lead has then led media scholars to apply, refine, and expand on his concepts.

Bourdieu $(1990,1998)$ tackles the objectivity-subjectivity problem at the heart of the humanities and social sciences. He calls the dichotomy a false one. Social life does not cleanly divide between objective and subjective, and methods that claim to focus on one side do so at their peril. Bourdieu's (2002) theory of practice instead "sought to develop a concept of agent free from the voluntarism and idealism of subjectivist accounts and a concept of social space free from the deterministic and mechanistic causality inherent in many objectivist approaches"(Johnson, 1993, p. 4). And his genetic sociology or structuralism "combines an analysis of objective social structures with an analysis of the genesis, within particular individuals, of the socially constituted mental structures which generate practice" (Johnson, 1993, p. 4).

But how does he bridge the divide between objectivist accounts of social life with subjectivist 
accounts of lived experience? His field theory is key to understanding genetic sociology. He does not doubt the objective existence of social structures that influence humans in day-to-day social relations. But when he uses the word objective, he does not mean unchanging or universal. Structures and relations are objective in the sense that they do not change at the whim of an individual. Media systems are objective structures, as are political systems, educational systems, and others. To avoid falling into vulgar determinism, Bourdieu argues that the presence of objective structures does not explain how humans come to understand their relationship with those structures. For that explanation, he developed his field theory.

"A field is a separte social universe having its own laws of functioning (Bourdieu, 1993, p .16 2). In any field, humans encounter norms and expectations that exist outside of their subjective experiences. A field is an objective structure that contains the rules for a specific subdivision of social life. Some fields achieve a level of independence from other fields. As Bourdieu describes the arts in one of his better-known works: Distinction, "The pure gaze is a historical invention linked to the emergence of an autonomous field of artistic production, that is, a field capable of imposing its own norms on both the production and the consumption of its products" (Bourdieu, 1984, p. 3). As fields become more important for social life, they also expand their capacity to set their own standards, terms, and expectations.

To explain how individuals come to know the rules of a field in subjective experience, Bourdieu developed a theory of practice. Three concepts—-habitus, social space, and symbolic capital — serve as the building blocks connecting agency to structure. If fields contain the rules of play, the habitus is one's feel for the game, a "practical sense"(Bourdieu, 1998, p. 25) that allows one to act and react in particular to life encounters situated in history. Habitus "is a set of dispositions which generates practices and perceptions"(Johnson, 1993, p. 5), a set of "cognitive 
motivating structures"(Bourdieu, 2002, p. 78; see also Bandura, 1986, 2001). Bourdieu explains: Habitus are generative principles of distinct and distinctive practices - what the worker eats, and especially the way he eats it, the sport he practices and the way he practices it, his political opinions and the way he expresses them are systematically different from the industrial owner's corresponding activities. But habitus are also classificatory schemes, principles of classification, principles of vision and division, different tastes. They make distinctions between what is good and what is vulgar, and so forth, but the distinctions are not identical. (Bourdieu, 1998, p. 8)

Bourdieu envisioned a social space where individuals situate themselves based on distinctions drawn from their habitus. But a distinction "is nothing other than difference, a gap, a distinctive feature, in short, a relational property existing only in and through its relation with other properties"(Bourdieu, 1998, p. 6). Social space exists because of subjective differences individuals place between themselves and others. It is constantly shifting as forms of capital take on different (subjective) value.

Value as socially constructed is an important marker for Bourdieu. By exercising their place in social space, individuals enact what Bourdieu $(1990,1998,1999)$ calls symbolic power: They create the structures they then use to dominate other individuals. The modes of domination are systematic structures that create positions of authority (Bourdieu, 1990, 2002) and legitimate the act of domination itself. Bourdieu calls the use of modes of domination symbolic violence (Bourdieu, 1998) because they are forcible domination without the use of physical force. The exercise of symbolic power creates symbolic capital, "any property (any form of capital whether physical, economic, cultural, or social) when it is perceived by social agents endowed with categories of perception which cause them to know it and to recognize it, to give it value" 
(Bourdieu, 1998, p. 47). Those in positions of dominance then concentrate and maintain their symbolic capital.

In media studies, scholars of journalism have applied Bourdieu's field theory to understand the development of newsroom norms and similar practices (Benson \& Neveu, 2005; Hesmondhalgh, 2006; Neveu, 2007), and scholars of media systems have drawn on it to show how institutional changes in one system relate to changes in another (Hallin \& Mancini, 2004). But comparative studies have not engaged the subjective element in Bourdieu's theory of practice. Field alone “cannot summarize Bourdieu. This concept must be considered" part "of a toolbox" (Neveu, 2007, p. 339). Bourdieu's analysis of Flaubert is instructive. Studying literature and art in a larger context or field engages in analysis is aimed only at "a macro-sociology," but doing so only for their effects on audiences engages in analysis aimed at "a Social micropsychology,"and both options proceed without ever truly establishing "a relation between the two"(Bourdieu, 1993, p. 162).

Other studies using comparative analyses of media and political systems operate exclusively at the macrolevel (e.g., Benson \& Hallin, 2007). Studies exploring the links between media use, content, and systems, as well as civic and political participation, have tended to the micropsychology level, relying on survey data (e.g., Pinkleton \& Austin, 2004), focusing on attitude measures (e.g., Wilkins, 2000), or looking for media effects (e.g., Zhang \& Chia, 2006), rather than accounting for subjective experiences more directly.

\section{Literature II: Macro- and microinteractionism}

In the early 20th century, Chicago sociologists began exploring the subjective experience of citizens as a way to understand social change and emerging media. William I. Thomas and Florian Znaniecki, in their groundbreaking work, The Polish Peasant (1927), gathered letters to 
the editor and other expressions of subjective states among the public and also solicited and analyzed a full-length autobiography, the first such sustained work in sociology, to understand society through subjective experience (Thomas and Znaniecki, 1972). Somewhat later, Herbert Blumer (1933) gathered hundreds of brief life histories to discover how the young understood and interacted with a new media form, the cinema. The early work started from pragmatist assumptions and employed the idea (later called symbolic interactionism) that the meanings of practices and institutions emerge through intra- and interpersonal communication in society. Scholars have recently made explicit attempts to "bridge between the audience experience and the media system" by examining life histories (Barnhurst, Sampedro, \& Cordeiro, 2006, p. 165). Life history researchers have asked young adult audience members to tell and interpret their stories in light of the media and political environments where they lived. An initial study found that newspapers did not speak to the political interests of U.S. young adults (Barnhurst \& Wartella, 1991). A follow-up study found that young Americans also rejected television news as a source of meaningful information (Barnhurst \& Wartella, 1998). A third study expanded beyond newspapers and television and found that U.S. young adults turned away from informational media generally, instead focusing on entertainment as a source of political engagement (Barnhurst, 1998). The results were clear, at least for young adults with more education and from white-collar families in the United States: They viewed news media as sources of factual information, but did not find them politically engaging. What could explain these microlevel responses? Were the media and political systems influencing subjective interpretations of political agency? Researchers turned to comparative analyses to discover answers to these questions.

The liberal U.S. media system contrasts with the polarized pluralist media system in much of 
Europe (Hallin \& Mancini, 2004). The U.S. media system has medium to high circulation newspapers, strong journalistic norms, and a commercial but ostensibly neutral press. The polarized pluralist media system of Spain, by contrast, has low newspaper circulation primarily targeting elites, weaker (or more literary) journalistic norms, a partisan press, and overt state intervention. A life history study comparing the two nations found that young adults in the United States experienced feelings of disengagement compared to those in Spain, who felt empowered with political options and choices (Barnhurst, 2000). Of course, the differences between American and Spanish young elites could have resulted from Spain's then-recent transition from dictatorship to democracy. Only further comparative study could assess the impact of political transition.

To control for political system changes, another study turned to Brazil, which, like Spain, experienced a transition to democracy at about the same time and also has had a politically engaged press (Barnhurst et al., 2006). But unlike Spain, Brazil has a media system that shares some aspects with those found in the United States, such as highly commercial television. Brazil represented an in-between case for comparison using the same life history methods. When young elites described and interpreted their subjective experiences within their media and political systems, Brazilians and Spaniards understood and learned from their political transitions similarly in some ways but differently in others:

The Brazilians ... respond with interest in, without focusing primarily on, political events. They also report an inclination to activism, but [unlike Spaniards] do not compare how different news outlets cover the same event. They join little collaborative dialogue about news. They express resentment toward (especially the audiovisual) media (perhaps in part because of ownership concentration), but [unlike Americans] are not primarily fearful or 
powerless. They find the commercial power of media to influence political movements ominous, but the media system does give them access to alternatives and options. (Barnhurst et al., 2006, p. 181)

The young Brazilian elites experienced parallel changes in their political system but did not resemble the Spaniards primarily because of "the distinct media systems" (Barnhurst et al.,2006, p.181). The highly commercial broadcast media contributed to a postmodern subjective attitude that aligned the Brazilians more with the Americans. Young elites from both countries adopted a similar subjective posture, primarily as consumers of mediated messages.

The comparative work initially focused on a relatively elite subset of the populace. If subjective experiences among the more advantaged in society come under observable influences of media systems, then what of the experiences among other socioeconomic groups? A subsequent study of the same media systems and political conditions gathered life histories among the working classes (Sampedro, Barnhurst, \& Cordeiro, 2004) and found that the Brazilians made only rare political references, responded to news events emotionally and with a sense of futility, and felt politically disempowered, unlike the Spaniards. Although working-class individuals in both nations, like their elite counterparts, were aware of the recent political transitions, no less-advantaged participants in either country showed a sense of themselves as independent from, or empowered to critique, media and political institutions. The consistency in method and cases exposes how social class also contributes to subjective positions in the face of the Spanish and Brazilian media and political systems. The research did not include workingclass participants in the United States.

The overall results of comparative analyses yielded two concepts to analyze the media audience for politics: subjective posture and subjective affluence (Barnhurst, 1999). Subjective 
posture is the role that individuals assume (as displayed in narrative) toward the communication system (mainly as audience members) and the political system (perhaps as citizens). One should not confuse subjective affluence with the use of the term in the economic literature as a statistical indicator of material wealth (e.g., Drewnowski, 1978), nor with "subjective experience of affluence or deprivation" as scholars use it in the consumer research literature (Ahuvia \&Wong, 1995, p. 173), nor with the term in the comparative political science literature referring to a perception of material wealth and comfort in early childhood (Inglehart, 1971, 1990).

\section{[Insert Table 1]}

Subjective affluence is the range of postures different individuals assume in public narratives about the media, displaying their degree of political interest, knowledge, and activity. The subjective postures previous studies observed had four dimensions related to identity, politics, information, and the media. Under different media and political systems the subjective affluence ranged from relatively marginal for conditions most emphasizing commercial life to relatively vital for conditions emphasizing political life (Table 1).

Subjective postures under the most commercialized conditions themselves contained a narrower polarity, usually from low to none (for references to political action, information sources, and discussion, for instance). The stances toward media range from reactive to resistant emotions (Vincent \& Fortunati, 2009). One question an examination of life histories from different social groupings can explore is whether conditions of education, advantage, and affluence themselves contribute to (and deepen the polarity within) the subjective postures centered less on politics found within the commercial U.S. media system.

\section{Methods: The life history technique}

Life history techniques grew out of autobiographical methods in Chicago sociology, which 
directed researchers to the subjective experiences of individuals and had a widespread and profound (if rarely acknowledged) "influence on all the social sciences" (Watson \& WatsonFranke, 1985, p. 6). Life history is a fairly standard approach to qualitative inquiry (Denzin, 1989; Denzin \& Lincoln, 2000; Tierney, 2000). Unlike documents such as an autobiography or diary, "the life history is any retrospective account" an individual creates in any form, "prompted by another person" (Watson \& Watson-Franke, 1985, p. 2). Unlike interviews, life histories are more or less public documents, and writers are free to document their own subjective accounts as they see fit. Researchers may gather limited life history documents by asking participants to focus on one topic, and this project asked participants to narrate their media experiences. Life histories are "a culturally produced artifact in one light and an interpretive document in another" (Tierney, 2000, p. 539). For insight into their objective life conditions we also asked participants to complete a questionnaire independently about their education, family background, and other specific demographic information related to politics and the media. Our methods aim to bridge the divide between the macro and micro: "While the subject is talking about experience, that is, experience with subjectively intended meanings, the investigator is talking about 'objective' events"(Watson \& Watson-Franke, 1985, p. 25). The documents and questionnaires allowed us not only to examine participants' subjective responses to their objective mediated and political circumstances, but also to build on previous studies employing the same methods.

Recruitment occurred during ordinary contacts or group meetings and through handouts posted and distributed to potential participants. The authors described the project and invited volunteers to participate in the study. Those interested then met with a researcher, who explained the project, its benefits, risks and voluntary quality, and the confidentiality policy. The 
recruitment process yielded 103 participants. All were residents of the metropolitan Chicago region and between 18 and 29 years old.

A set of instructions asked participants to write about their experiences with the media and public life. Most produced a three- to five-page life history document working independently, deciding when and where to write and which experiences and details to include. A researcher was available to answer questions or, in cases of participants with less literacy, to transcribe the account as told by the participant, who then reviewed, revised, and approved the text. ${ }^{1}$ Based on the completed questionnaires, the demographic distribution of participants was surprisingly balanced. There were somewhat more men (56\%) than women (44\%). Participants identified themselves as White (29\%), African American (29\%), Latino (21\%), Asian American (17\%), and other (4\%), a racially diverse array. For education levels, a majority of respondents said they completed some or all of high school (56\%), and the rest said they had attended or completed college. We used responses about their formal education, current occupation, and parents' education to classify participants as either more (57\%) or less (43\%) advantaged.

After collecting the documents, we converted them into text files for archiving, coding, and searching using qualitative analysis software. To assure the reliability of coding, we adopted a consensus procedure that other life history studies used (Barnhurst \& Wartella, 1991; Barnhurst et al., 2006). First one researcher read each of the documents and identified recurring themes used to create an initial coding scheme. A second researcher then read the documents and the coding framework and offered suggestions, and so forth until all three researchers reached consensus. The approach is similar to Blumer's (1933) inductive technique for analyzing biographies. To code the life histories at the sentence level, we paid particular attention to categories and themes related to subjective affluence, such as changes in the broader context (life 
decisions), statements of political engagement, opinions the author considered important, and indications of choice or agency and action (political as well as economic).

Analysis followed coding. We used the software to generate intersect reports, which allow researchers to select segments of text from the documents systematically. For example, we drew a report of the intersection between perceived political agency in the coded sentences and socioeconomic status in the questionnaires. We inspected all textual fragments from documents containing intersections. The life histories thus connect socioeconomic status, "memory, and history to reflexive political action" (Denzin and Lincoln, 2000, p. 374). Besides describing the Chicago participants, the analysis also permitted us to compare the results to those from the Spanish and Brazilian life history studies.

\section{Results: Less- versus more-advantaged life histories}

The following brief examination divides the narrative documents into two groups, those from less- and those from more-advantaged backgrounds. All the participants would likely call themselves middle class, following custom in America, but their education and literacy, as well as family income and employment, distinguish the less-advantaged participants from those we call more-advantaged participants, usually college educated from white-collar families. (For each participant quoted in the text, the identification includes only personal information the author provided and gave release to include.)

Our aim here is descriptive, to explore the patterns of the narratives from the two groups. We expect the American young adults to have similarities in their subjective postures, living under common media and political systems. But the more-advantaged participants might adopt a somewhat different stance toward politics, information, and the media because clear political differences emerged between classes in the study in Spain (Sampedro et al., 2004). In this study, 
the participants took a primary identity as consumers, in line with the highly commercial U.S. system, where even politics has taken on marketing approaches. But their stances toward their own political and media activities differed somewhat by grouping, especially regarding information.

\section{Results A: Identity}

The subjective postures of the two groups began from identities focused on their sense of economic choice. Elements of consumerism saturated the participants' life histories. Deneatra, an African-American working-class woman, offered an account from her childhood that begins with a simple statement: "I think I have been influenced by the television for as long as I can remember," especially one aspect: "I know it might sound strange, but commercials have been a main part of my entertainment when I watch TV for a very long time." She grew up watching them and remembers as a toddler staying quiet only during commercial breaks, a habit that constantly interrupted her father's favorite shows. For her, the ads were enjoyable. "I paid so much attention to commercials, I would make my own" while she and her sister would play with their mother's makeup, Deneatra would pretend to be a model selling the newest cosmetics. She used advertising to inform herself before making purchase decisions, seeking out and lingering over fashion ads to know what to buy when shopping. In high school, she recalls watching commercials to prepare before shopping for clothes with her mother. Her involvement was an acceptance of self-as-consumer. She embraced the identity.

Advantaged participants likewise wrote narratives full of consumerism. Consider the story of Alex, a White college student, who also noted how the media helped her decide what purchases to make. She begins her essay by describing her sister as the fashionista of the house, a role that grew from a habit of reading Seventeen and Teen. Eventually, Alex began reading the same 
glossy monthlies, using them as guides for shopping:

I started skimming through magazines to see what other people were wearing. Once, I saw a pair of shoes that I adored. I cut out the picture and asked my mother to take me to the store and get them for me.

She also focused her attention on media figures to help her decide what to buy and how to clothe herself. Because "the models were perfect symbols of beauty," their choices seemed good guides for the best purchases and dress. She shows no unease about using media targeting teenagers and the ideal of fashion models appearing there as sources for self-expression. Like Deneatra and Alex, the participants saw themselves clearly as consumers. In coding economic categories, sentences that reflected an understanding of "economic choice," for instance, were present in $25 \%$ of less-advantaged and $29 \%$ of more-advantaged participants' life histories. The essays tend to place their choices about personal perspectives, appearance, and behaviors into the category of the market. Their identity, a key aspect of subjective posture in their narratives of media and politics, dwells comfortably in the position of the consumer.

\section{Results B: Politics}

In positioning themselves in the political world, however, the narratives differed somewhat for the participants. To illustrate, we turn to Vattanasinh, 18, a working-class Asian male. Media influenced his becoming American, he says, and "television was a big part of my life as a child; I've learned a lot of interesting facts and my English improved from television." He turned to TV not only for information but also for entertainment. Although he considered fiction shows good sources "about the American culture and traditions," he judged nonfiction programs negatively. "Politics was never a big thing to me and still isn't," he writes, "I feel it's a bunch of powerful people making promises to do things that they have no control over." He greeted news 
broadcasts with cynicism.

In contrast, Roberto, a gay college student, found the political more of interest, but not through mass media. He describes television as "a source of "realism"” not necessarily grounded in truth. As a youth he spent time watching television, and he remembers few positive portrayals of gays: "just visions of men perceived as immoral human beings or humorous sidekicks."

Without realizing it, he began searching for some other foundation, a lens for viewing politics in the life world. "I wanted to become a person who accepted everyone for who they were, whether I agreed or not, and in a sense treat them as the person they could become." He found a lens not on television but instead in books. "Through these readings, my self-esteem had increased and I was becoming someone I was proud of. This gave me the power to show others what I had become and help others find their way." He took what he learned and, instead of turning inward, looked for how to be of service. He reports the ability to engage politically beyond himself. His experiences with television do not contradict the stories Vattanasinh and other lessadvantaged participants tell. Roberto considered television a negative example of politics. The media portrayals of men like him did not empower him. His alternative route, through books, led him to self-fulfillment and a desire to serve others, despite being short on specific actions. In general, participants described a stance toward politics consistent with previous research (Barnhurst \& Wartella, 1991). Little in the political content of print or broadcast news media addressed any of their concerns. Especially the less-advantaged participants saw news and political messages as boring, and the better-advantaged volunteers wrote more about reaching out to others, making the interpersonal political. In coding for participants' understanding of “politically engaging" content, we found only $18 \%$ of the less-advantaged participants wrote about taking an active political interest (a mere 11 sentences). Among the better-advantaged 
participants, 53\% expressed higher levels of involvement and interest in politics (in 166 sentences, with more than 5 sentences on average per essay), illustrating an engaged subjective stance. A similar pattern held for sentences about "increasing activism" and related coding.

\section{Results C: Information}

All participants expressed a general awareness of using media information to make nonconsumer choices as well. Both groups recounted instances of changing their actions after learning from the media. They treated the information as a tool for living. But less-advantaged participants usually applied media content to their personal choices only. The more-advantaged participants could extend their learning beyond themselves to others. Two examples of media information about teen pregnancy can illustrate the different reactions, as well as how an issue can lose its connection to political action when becoming personal.

Elizabeth, 25, a working-class single mother, gave birth to her daughter Samantha at age 17. She had not planned her life that way. Coming from a large family, the youngest of nine children, she says others picked on her in childhood, but her parents paid little attention. She writes

Unfortunately, my parents never told me about the dangers of life, meaning my mother had never given me "the talk." I knew what was wrong and right, but had no clue how severe the consequences to my actions might be. The little I did know was from watching television.

Note how her story takes a moral position and dwells on the personal impact. A major decision she made - the choice to keep her baby — she attributes to the guidance of television: On the news she "saw a lot about abortion clinics and the people that were against them," protesting. Based on that information, she "decided to keep the life inside me and vowed to be the best 
mother I could." The information helped her make a difficult choice, but she saw her options as restricted to individual behavior. The alternatives related to her health and family, not to "choice" with an outwardly political perspective.

The more-advantaged participants' life histories talk about action beyond their private or personal lives as one of their choices. Nancy, a 19-year-old Korean participant from a more comfortable background, describes how movies and television showed her the freedoms American woman enjoy compared to Koreans. In the United States she had many more personal alternatives open to her than did women like her in Korea, she says. But her media learning did not end at realization. An episode of Oprah informed her that her wider array to choose from also came with consequences (note the parallel to Elizabeth's framing). Nancy writes:

I saw lots of teenage girls getting pregnant, the pain and suffering they were going through because they had a child so young. There's so much you couldn't do because you have to be responsible for your kids.

The program, as well as others such as the Jerry Springer and Howard Stern shows, informed her own decisions and expanded her worldview at the same time, allowing her to conjecture about events going on beyond her personal experience. She says:

I think the reason why there are so many girls getting pregnant is because men see girls as sexual objects and not as a human being. If they really cared about the girl they are sleeping with, the men would have tried to use a condom so the girls won't have to suffer so much.

Here Nancy reasons about the general case, but by making judgments she applies to others. Teen pregnancy is more a failure of caring and action on the part of men. Her essay tells another story of learning about the dangers of plastic surgery through television, and again she expands 
her personal decision to a larger statement: "I'm happy with the way I look. To go through that kind of risk just for beauty just isn't worth ${ }^{\text {it." }}$

Her stance treats media content as information, and, typical of other advantaged participants, she generalizes from her own experience. All the narratives expressed a general awareness of how information influences them, and the difference between participants from the two classes is a matter of degree. In other research, middle-class and working-class women likewise differed qualitatively when reasoning about the issue of abortion (Press, 1991). The less-advantaged participants' essays take a moralistic position and their more-advantaged counterparts still focus on individual shoulds, not necessarily framed by explicit morals (or institutional politics either), whether or not the moral and political are intrinsic to the issues.

\section{Results D: Media}

An important way the participants narrate their life histories is by presenting media primarily as venues for entertainment. Consider two cases of more- and less-advantaged participants who focus on stories about sports. Chris, an affluent college student living in the suburbs, begins his life history by noting how, "like many children of similar background, many of my earliest childhood memories revolve around the television set." What he remembers most is watching not news or political events but other diversions on television. He "found consolation in its comforting images and its unmatched entertaining qualities." Of particular interest was sport, and watching the Buffalo Bills play during the 1991 Super Bowl was a highlight. He recalls the emotional involvement he felt, with neighbors and family members "clutching each other at crucial moments" during the game. "It was strange, as I look back now upon that moment," he writes, "my whole existence became centered on something so out of my control on that night." Studies of television use report that elites manage and measure their consumption of television 
programming (Jordan, 1992; Morley, 1986), and television use ties closely to family dynamics and group interactions in elite and nonelite groups alike. Sports on television provided a way for more-advantaged participants to identify with those around them and fit into social space (where the expectation of control remains).

Noe, 22, a working-class Mexican American, grew up in the city center, not the suburbs. Like Chris, he begins his life history by examining how television influenced his life. When facing pressures to join a gang, he found solace in baseball. He became a fan of the Los Angeles Dodgers and "enjoyed watching Pedro Guerrero play," one of the few good influences in his experience. "After watching baseball on television and falling in love with the game, I had a new, fresh outlook on life. Becoming a baseball player was the first positive goal I had in life." Television was the source of enjoyment that supplied him with escape and also something to dream for (and a sense of control that came as a surprise). He writes about emotion, his love of the game, and the joy of fresh prospects, but also about individualism in resistance to groups. Noe also liked photojournalism but turned to broadcast diversions to situate himself in social space. Like Chris and the others, Noe uses his life history to reflect the ubiquity of entertainment. Although the two examples gave sports a prominent place, others described individual preferences for a range of entertainment content. In coding we found nonpolitical "interests" in $41 \%$ of less-advantaged and 39\% of more-advantaged participants, including a substantial number of sentences (averaging 21 and 18, respectively, per narrative). Participants, regardless of other advantages, made fiction and pleasure important elements in their life history accounts when turning to the subject of the media. Emotion was a center of their subjective understanding of the media, especially coziness in the case of television. Previous life history studies showed that the media are a focus of emotional experience, a comfort zone in a challenging world 
(Barnhurst \& Wartella, 1998).

\section{Results: Summary}

Identity, politics, information, and media interlock in the life history narratives. The participants tell stories about a topic they found important, and they weave media (broadly defined), information, and politics into their identities. We have unraveled the nexus to explore prominent similarities and differences across group lines. The participants are first Americans and share many qualities, and they differ from Brazilians, Spaniards, and others in previous studies. But within the unity of their common media and political experiences, a clear pattern of similarity and difference emerges. When it comes to the matters they define as personal, such as their own identity but also the experiences with media, the life histories are fairly uniform, with agreement that crosses socioeconomic lines. Narratives by more- and less-advantaged participants adopt a posture that includes a consumer identity and looks to the media for emotional satisfaction and entertainment.

But for matters they treat as experiences in public life or as life in public, such as the domains of politics and information, the life histories diverge somewhat. More-advantaged participants' narratives expand beyond personal experience to generalize, where less-advantaged participants' narratives remain personal. The stories each social class tells reflect the different resources available by opening up or preempting opportunities to help or influence others. But the participants treat problems and solutions as matters of individual choice (in line with a consumer identity), in contrast to the partisanship or ideologies present in the life histories from Spain, Brazil, and other countries with overtly political media systems.

\section{Discussion: Life history and Bourdieu}

In reporting results from the life history technique, we deferred specific reference to concepts 
from Bourdieu to demonstrate the qualities of observation available from the Chicago School tradition, but the two perspectives do intersect. The life histories describe elements from the practical reason of the participants as young adults in America. They have much in common, especially the personal, emotional, entertainment, and consumer elements of their stories. And they differ in how they talk about politics and information, just as Bourdieu would expect different classes to differ systematically. But practical reason is a broad principle guiding a comprehensive range of life practices. The limited life history technique takes a specified slice of life, making it possible to identify and explore the stances particular to a segment of the full biography. The subjective postures that emerge in the documents show a patterned response to the surrounding media and political systems.

Bourdieu was especially interested in social space as a common location where distinctions play out, and here our study also intersects. For instance, the scope of action open to them distinguishes the study participants. Less-advantaged participants' life histories recount political and informational transfers through the media that occasion personal choices, where the moreadvantaged participants' histories follow that logic and then take it a step further, into a generalized urge to extend that learning beyond the self and influence others. The betteradvantaged participants refer to their own symbolic power, although they couch it in a personal service vocabulary (Eliasoph, 1998), expressing desires to convey information or help others. But the participants also reveal the larger arena (to use Blumer's term) where power operates, through the media and politics. These intersecting areas maybe fields in the sense Bourdieu would recognize, and, for the professionals and politicians working within them, they may also be independent and relatively autonomous fields. Media owners and practitioners to some degree negotiate and work within the rules of their own game, as do politicians. Young adults may sense 
the echoes of those negotiations, but their rules of play emerge from life-worlds removed from the two fields. In Bourdieu's terms, the interactionist arena of politics and media is an objective structure that limits program production and distribution, as well as the population of celebrities and authoritative institutions, all of which the study participants encounter as if from afar. In subjective experience, some individuals see only take-it-or-leave-it options, and others find resources to imagine doing more. Like the Americans in previous life history studies, the participants preferred to reject authoritative kinds of media content, such as news of politics, and to accept entertainment content, especially when they considered it informative. They seem to have insulated themselves from the political and media modes of domination, in Bourdieu's terms, while leaving themselves open to the possibilities of symbolic violence inherent in entertainment and consumerism, where advertisers and celebrities assign and acquire value (symbolic capital) from audiences.

The less-advantaged participants turned the lessons from entertainment programs in on themselves, but the more-advantaged participants found ways to extend those lessons to others. That difference in what Bourdieu calls symbolic capital occurs along a range that life history research refers to as subjective affluence. In our study, the less-advantaged participants occupy a marginal point along that spectrum. But the more-advantaged participants, under the rich commercial U.S. media system, are not much better off. They tend to align themselves with existing power, becoming subject to the consumer perspective and entertainment media and also becoming the agents spreading media information to others. But the more-advantaged participants also describe somewhat more political understanding and point to ways of circumventing popular media and mediated politics.

Life history research in the Chicago sociological or interactionist tradition extends Bourdieu 
by providing access to an important aspect of the habitus, the subjective postures of study participants. Bourdieu's habitus is all encompassing and may include subjective states in relation to a wide variety of actions as well as inaction (or contemplation) across fields. Subjective posture is useful because it brings forward the participant's public stance. The participants, by writing a document for research, archiving, and potential publication, are making their subjective views manifest. The public dimension is important to the study of politics and the media, and life histories make public stances observable (unlike the private zone of interviews or surveys). Researchers might discover habitus through lengthy fieldwork, but life history documents concentrate the task of understanding on an aspect of habitus.

Life history work also connects subjective experience to larger objective structures, in the spirit of Bourdieu, by comparing experiences of relatively different subjective affluence. Symbolic capital is a broad concept that may include a full range of distinctions (economic and social, manifest and latent, and so forth) growing out of the habitus and available to members in a field. Subjective affluence is useful, especially for studying politics and the media, because it compares the postures of groups based on patterns in the overt statements they make in their life history accounts. Rather than relying on institutional change as a barometer, life history research draws evidence from subjectivities within a system. Bourdieu (1998, p. 3) noted the importance of "different collective histories" In understanding the relationships between objective structures and subjective experience. The interactionist life history technique makes collecting those histories a manageable task that can accumulate a larger picture of fields and practical reason through subjective accounts.

\section{Conclusion: Similarities, differences, and sociological outcomes}

In sociological terms, similarities in the subjective experiences of elite and nonelite members of 
the same country tend to reveal aspects of the systems surrounding both groups. Differences emerge because of the unequal social conditions of the groups, which may include differential access to or voices within media and political systems as well. Where media systems are powerful, one might expect more uniform subjective responses despite differences in personal life conditions. But differences are especially interesting because they reveal patterned advantages and drawbacks the participants experience under the same media and political systems.

In the ongoing project of life history research, we have contributed a nonelite dimension in subjective experiences within the U.S. media and political systems. Compared to moreadvantaged participants' life histories, the less-advantaged participants were less often active political agents in their essays. They considered news either depressing or irrelevant to their lives, and they consulted fewer sources and focused action on themselves. Conversely, the advantaged participants reflected a somewhat more varied array of responses to the surrounding systems. They found in the media some prospects for political action and also saw the potential for change beyond themselves. We attribute these differences primarily to the socioeconomic conditions - including income, education, and family backgrounds that the participants reported in questionnaires as well as their essays - because nothing in the documents suggests differential contact with larger systems.

But both groups viewed media similarly as sources of entertainment. Previous life history work involving elite U.S. participants noted a blurring of the divide between information (especially political) and entertainment (Barnhurst, 1998), one quality or outcome of the U.S. media system. In our study, both groups also conveyed a clear involvement in consumerism through their essays. Despite differing concrete life opportunities and subjective stances, the 
participants were equals under media (and, to a lesser degree, politics) that focused on audiences as consumers.

Putting the findings of this article into conversation with the other results from elite and working-class participants in Brazil and Spain adds to the comparative understanding of media and political systems. Our results confirm earlier suspicions: U.S. participants, living in an objectively more commercial media system, have subjective experiences that position individuals as consumers, a finding similar to how the Brazilians experienced their highly commercial system of broadcasting. In comparison to Spaniards living with diverse political views directly tied to media outlets, U.S. participants did not perceive as much political variety in the news. The previous studies showed that the differences arose from the systemic structures of media and politics in different countries. In the case of Brazil, socioeconomic class clearly aligns with aspects of the system—nonelites watch television and listen to radio while elites also read the press - resulting in relatively large differences in subjective affluence. This study confirms that smaller differences in subjective affluence also obtain from socioeconomic conditions within one country with less pronounced media use differences. The prospect the life histories present is hopeful in light of studies in other countries, which show that young adults have greater subjective affluence under overtly political and less-commercial media systems. The study of subjectivities through life history documents can provide a window on experiences with media and political systems. Staying close to the interpretations of audiences imposes a kind of discipline that would benefit theory building of the grand, Four Theories sort (Siebert et al., 1956) and also makes the connections between the life-as-lived (-and-understood) level and the systemic level, which recent work on comparative media systems admires (Hallin \& Mancini, 2004). 
Although growing from distinct theoretical pedigrees, Chicago School sociology and the sociology of Bourdieu are not necessarily adversaries. Bourdieu adds clarity about the objective structures constraining lived conditions within media and political systems, and Chicago sociology extends the understanding of "field" to include those who exist outside but participate indirectly in its productive domain and who create their own spaces from the output of the field's insiders. Life histories avoid the "voluntarism and idealism of subjectivist accounts" from other methods (Johnson, 1993, p. 4). In short, interactionism can help fill in the interstices of field theory and practical reason, and Bourdieu can help provide a framework for building theory from documented subjective experience.

\section{Acknowledgments}

A faculty scholar award at the UIC Great Cities Institute supported fieldwork and initial data analysis for this project. The authors wish to thank the many student volunteers and Chicagoarea participants who contributed the time and energy that made this project possible.

\section{Note}

The project aimed to respect the rights of participants, who could decide whether to add their document to an archive (either at a library or on a network site) and, if so, whether to release their names and whether to hold copyright. Researchers encouraged them not to reveal sensitive information, especially if they intended to identify themselves. All participants who finished writing the life history received a small payment $(\$ 45$, no matter whether they identified themselves, completed the questionnaire, joined an archive, or retained copyright).

\section{References}

Ahuvia, A., \& Wong, N. (1995). Materialism: Origins and implications for personal well-being. European Advances in Consumer Research, 2, 172-178. 
Altschull, J. H. (1984). Agents of power: The role of the news media in human affairs. New York: Longmans.

Bandura, A. (1986). Social foundations of thought and action: A social cognitive theory. Upper Saddle River, NJ: Prentice Hall.

Bandura, A. (2001). Social cognitive theory of mass communication. Media Psychology, 3, 265299.

Barnhurst, K. G. (1998). Politics in the fine meshes: Youth, power \& media. Media, Culture \& Society, 20, 201-218.

Barnhurst, K. G. (1999, November). Life history, identity, and the media: Toward a theory of subjective response. Paper delivered at the 85th Annual Convention of the National Communication Association, Chicago, IL.

Barnhurst, K. G. (2000). Political engagement \& the audience for news: Lessons from Spain. Journalism \& Communication Monographs 2 (1 Spring). Columbia, SC: Association for Education in Journalism \& Mass Communication (AEJMC).

Barnhurst, K. G., \& Nerone, J. (2001). The form of news, a history. New York: Guilford.

Barnhurst, K. G., Sampedro, V., \& Cordeiro, T. (2006). “The press motivated me”: Life histories with media in Brazil. Communication Review, 9, 163-187.

Barnhurst, K. G., \& Wartella, E. (1991). Newspapers and citizenship: Young adults' subjective experience of newspaper. Critical Studies in Mass Communication, 8, 195-209.

Barnhurst, K. G., \& Wartella, E. (1998). Young citizens, American TV newscasts and collective memory. Critical Studies in Mass Communication, 15, 279-305.

Benson, R., \& Hallin, D. (2007). How states, markets and globalization shape the news: The French and U.S. national press, 1965-97. European Journal of Communication, 22, 27-48. 
Benson, R., \& Neveu, E. (Eds.) (2005). Bourdieu and the journalistic field. Cambridge, UK:

Polity Press.

Blumer, H. (1933). Movies and conduct. New York: Macmillan.

Bourdieu, P. (1984). Distinction: A social critique of the judgment of taste (R. Nice, Trans.).

Cambridge, MA: Harvard University Press.

Bourdieu, P. (1990). The logic of practice (R. Nice, Trans.). Palo Alto, CA: Stanford University Press.

Bourdieu, P. (1993). The field of cultural production: Essays on art and literature (R. Johnson, Trans.). Irvington, NY: Columbia University Press.

Bourdieu, P. (1996). On television (P. P. Ferguson, Trans.). New York: New Press.

Bourdieu, P. (1998). Practical reason: On the theory of action. Palo Alto, CA: Stanford University Press.

Bourdieu, P. (1999). Language and symbolic power (J. B. Thompson, Ed.; G. Raymond \& M. Adamson, Trans.). Cambridge, MA: Harvard University Press.

Bourdieu, P. (2002). Outline of a theory of practice (R. Nice, Trans.). Cambridge, UK:

Cambridge University Press.

Denzin, N. K. (1989). Interpretive interactionism. London: Sage.

Denzin, N. K., \& Lincoln, Y. S. (2000). Introduction: The discipline and practice of qualitative research. In N. K. Denzin \& Y. S. Lincoln (Eds.), Handbook of qualitative research (pp. 1-28). London: Sage.

Drewnowski, J. (1978). The affluence line. Social Indicators Research, 5, 263-278.

Eliasoph, N. (1998). Avoiding politics: How Americans produce apathy in everyday life. Cambridge, UK: Cambridge University Press. 
Graber, D. (2006). Briefly noted. [Review of the book Comparing media systems]. Political Psychology, 27, 935-936.

Guillory, J. (2000). Bourdieu's refusal. In N. Brown \& I. Szeman (Eds.), Pierre Bourdieu:

Fieldwork in culture (pp. 1-43). New York: Rowman \& Littlefield Publishers.

Hallin, D. C., \& Mancini, P. (2004). Comparing media systems: Three models of media and politics. Cambridge, UK: Cambridge University Press.

Hesmondhalgh, D. (2006). Bourdieu, the media and cultural production. Media, Culture Cr Society, 28, 211-231.

Inglehart, R. (1971). The silent revolution in Europe: Intergenerational change in post-industrial societies. American Political Science Review, 65, 991-1017.

Inglehart, R. (1990). Culture shift in advanced industrial society. Princeton, NJ: Princeton University Press.

Johnson, R. (1993). Editor's introduction: Pierre Bourdieu on art, literature and culture. In P. Bourdieu (Ed.), The field of cultural production: Essays on art and literature (pp. 1-28). Irvington, NY: Columbia University Press.

Jones, T. M. (2008). Book review [of Comparing media systems]. Comparative Political Studies, 41, 128-131.

Jordan, A. B. (1992). Social class, temporal orientation, and mass media use within the family system. Critical Studies in Mass Communication, 9, 374-395.

McQuail, D. (2005). Book review [of Comparing media systems]. European Journal of Communication, 20, 266-268.

Morley, D. (1986). Family television: Cultural power and domestic leisure. London: Comedia. Nerone, J. (Ed.) (1995). Last rights: Revisiting four theories of the press. Urbana: University of 
Illinois Press.

Neveu, E. (2007). Pierre Bourdieu: Sociologist of media, or sociologist for media scholars? Journalism Studies, 8, 335-347.

Pinkleton, B. E., \& Austin, E. A. (2004). Media perceptions and public affairs apathy in the politically inexperienced. Mass Communication \& Society, 7, 319-337.

Press, A. L. (1991). Working-class women in a middle-class world: The impact of television on modes of reasoning about abortion. Critical Studies in Mass Communication, 8, 421-441.

Sampedro, V., Barnhurst, K., \& Cordeiro, T. (2004). Medios comerciales y ciudadanos de segunda [Commercial media and secondary citizens]. Política y Sociedad, 41(1), 77-88. Siebert, F. S., Petersen, T., \& Schramm, W. (1956). Four theories of the press. Urbana: University of Illinois Press.

Thomas, W. I., \& Znaniecki, F. (1927). The Polish peasant in Europe and America (2 volumes). New York: Knopf.

Tierney, W. G. (2000). Undaunted courage: Life history and the postmodern challenge. In N. K. Denzin \& Y. S. Lincoln (Eds.), Handbook of qualitative research (pp. 537-554). London: Sage. Vincent, J., \& Fortunati, L. (2009). Electronic emotion: The mediation of emotion via information and communication technologies. Oxford: Peter Lang.

Watson, L. C., \& Watson-Franke, M. B. (1985). Interpreting life histories: An anthropological inquiry. New Brunswick, NJ: Rutgers University Press.

Wilkins, K. G. (2000). The role of media in pubic disengagement from political life. Journal of Broadcasting \& Electronic Media, 44, 569-580.

Zhang, W., \& Chia, S. C. (2006). The effects of mass media use and social capital on civic and political participation. Communication Studies, 57, 277-297. 
Table 1 Range of Subjective Affluence

\begin{tabular}{|c|c|c|}
\hline & Commercialized System & Politicized System \\
\hline Identity & Consumers & Citizens \\
\hline \multicolumn{3}{|l|}{ Politics } \\
\hline Involvement with politics as & Passive observers & Self-conscious actors \\
\hline Level of political discussion & Little or none & Engaged in dialogue \\
\hline Political activities & Few or none & Fairly frequent \\
\hline \multicolumn{3}{|l|}{ Information } \\
\hline Approach to information & Happened upon & Sought actively \\
\hline Sources of information & One or none & Several \\
\hline Uses of information & Received & Actively compared \\
\hline $\begin{array}{l}\text { Social interaction and } \\
\text { interpretation }\end{array}$ & Little or none & Warm collaboration \\
\hline \multicolumn{3}{|l|}{ Media (press or newscasts) } \\
\hline Stance toward news media & Reverent or indifferent & Detached or critical \\
\hline Emotions connected with news & Powerless or fearful & Dismissive or angry \\
\hline
\end{tabular}

